\title{
Renal Dysfunction Caused by Oral Sodium Phosphate Tablets for Colonoscopy
}

\author{
Takashi Uchiyama Masahiko Inamori Hiroshi lida Hiroki Endo Kunihiro Hosono \\ Tomoyuki Akiyama Hirokazu Takahashi Tomoko Koide Chikako Tokoro Masato Yoneda \\ Koji Fujita Ayumu Goto Yasunobu Abe Norioshi Kobayashi Hiroyuki Kirikoshi \\ Takeshi Shimamura Kensuke Kubota Satoru Saito Atsushi Nakajima \\ Gastroenterology Division, Yokohama City University School of Medicine, Yokohama, Japan
}

\section{Dear Sir,}

A 64-year-old man was admitted to our hospital for a colon polyp resection. He had a normal serum creatinine level at baseline $(1.0 \mathrm{mg} / \mathrm{dl})$, and his previous medical history was unremarkable with the exception of hypertension, which was being managed with a calcium receptor blocker. He received oral sodium phosphate tablets as part of the presurgical bowel preparation. An endoscopic polypectomy was performed without any difficulties. However, 1 day after the bowel preparation and colonoscopy, the patient's serum creatinine level increased $(2.11 \mathrm{mg} /$ dl). Supportive treatment was given, and the patient's creatinine level gradually decreased to normal over the course of 8 weeks after reaching a peak level of 3.10 $\mathrm{mg} / \mathrm{dl}$ on day 4 after the colonoscopy.
Acute phosphate nephropathy has been previously described as a possible complication after the use of oral sodium phosphate or phosphorus-containing medications [1]. The risk factors for acute phosphate nephropathy include an advanced age, pre-existing renal impairment, and the use of drugs such as angiotensin-converting enzyme inhibitors and angiotensin-receptor blockers [2]. However, our patient had none of these established risk factors.

In conclusion, oral sodium phosphate tablets should be administered with caution not only in older patients and those with established risk factors, but in all patients to avoid the risk of acute phosphate nephropathy.

\section{References}

1 Desmeules S, Bergeron MJ, Isenring P: Acute phosphate nephropathy and renal failure. $\mathrm{N}$ Engl J Med 2003;349:1006-1007.

2 Sica DA, Carl D, Zfass AM: Acute phosphate nephropathy: an emerging issue. Am J Gastroenterol 2007;102:1844-1847.

\section{KARGER}

Fax +4161306 1234 E-Mail karger@karger.ch www.karger.com www.karger.com/dig
Masahiko Inamori, $\mathrm{MD}, \mathrm{PhD}$

Gastroenterology Division, Yokohama City University School of Medicine

3-9 Fukuura, Kanazawa-ku, Yokohama 236-0004 (Japan)

Tel. +81 45787 2640, Fax +81 457843546

E-Mail inamorim@med.yokohama-cu.ac.jp 